\title{
ESTUDO DO USO DA LIGNINA-PEROXIDASE PARA REMOÇÃO DE 2-CLOROFENOL EM EFLUENTE LÍQUIDO
}

\author{
J. M. DE OLIVEIRA ${ }^{1}$, A. A. MORANDIM GIANNETTI ${ }^{1}$, A. C. LUCARINI ${ }^{1, *}$ \\ ${ }^{1}$ Centro Universitário FEI, Departamento de Engenharia Química \\ *E-mail: lucarini@fei.edu.br
}

\begin{abstract}
RESUMO: Neste trabalho foi estudado o uso da lignina-peroxidase para remoção de 2clorofenol em efluente líquido. Foi proposta a biorremediação enzimática por processo descontínuo de efluente contendo $20 \mathrm{mg} / \mathrm{L}$ de 2-clorofenol, utilizando concentrações de lignina-peroxidase (LiP) entre 0,012 e 0,026 $\mathrm{mg} / \mathrm{mL}$ e de peróxido de hidrogênio $\left(\mathrm{H}_{2} \mathrm{O}_{2}\right)$ entre 10 e $50 \mathrm{mmol} / \mathrm{L}, 30^{\circ} \mathrm{C}$ e pH igual 4,2. Foram realizados 4 ensaios sendo coletadas amostragens para os tempos de reação de 2, 4, 8,12 e 24 h. Análises cromatográficas revelaram $96,5 \%$ de redução do 2-clorofenol quando empregadas concentrações de $0,026 \mathrm{mg} / \mathrm{mL}$ de LiP e $50 \mathrm{mmol} / \mathrm{L}$ de $\mathrm{H}_{2} \mathrm{O}_{2}$. Resultados eficazes foram observados somente após 24 h de tratamento, independente das concentrações de LiP e $\mathrm{H}_{2} \mathrm{O}_{2}$. Análises via CG/MS revelaram possíveis formações de benzaldeído e ácido ftálico e confirmou-se o consumo praticamente total de todo o 2-clorofenol após 24 horas de tratamento na condição ideal.
\end{abstract}

PALAVRAS-CHAVE: Lignina peroxidase; 2-clorofenol; Biorremediação enzimática; Biotransformação.

\section{INTRODUÇÃO}

O crescimento mundial dos setores industrial e agrícola ocasionou inúmeros impactos ambientais, principalmente devido à disposição no ambiente de diversos compostos químicos utilizados em processos industriais e na agricultura que não participam dos ciclos naturais do carbono, do nitrogênio e do oxigênio, tais como: pesticidas, herbicidas, fungicidas, antissépticos, tintas e resinas, solventes e produtos farmacêuticos; e que tendem a se acumular no ambiente. As elevadas quantidades e a disposição inadequadas destes materiais no ambiente tem gerado um problema de poluição ambiental e de saúde pública (TANDJAOUI et al., 2016).

Neste contexto, o poder nocivo destes compostos, grupo no qual os organoclorados, tais como os clorofenóis se enquadram, só foi percebido após anos da sua utilização e, desde então, estudos vêm sendo feitos em vista de reduzir ou minimizar a quantidade dos componentes tóxicos e recalcitrantes liberados ao ambiente. Destacam-se os processos avançados de oxidação, o uso de solventes orgânicos, os processos de adsorção como os que utilizam carvão ativado, os processos de degradação microbiana, os processos de degradação fotoquímica, os processos de decomposição térmica catalisada e o uso de enzimas como 
catalisadores potenciais para a degradação de compostos fenólicos, como as peroxidases que podem levar a decomposição do mesmo até dióxido de carbono e água (TANDJAOUI et al., 2016; AJEEL et al., 2015; GAO; TEPLYAKOV, 2014; FREIRE et al., 2000; FLOCK et al., 1999).

Dentre as atividades que contribuem com grande parcela do processo de contaminação estão: as refinarias de petróleo, as indústrias químicas, a indústria têxtil, a indústria de papel e celulose, as atividades agrícolas, os esgotos sanitários e os resíduos domésticos (FREIRE et al., 2000) sendo que, em regiões desenvolvidas industrialmente, como é o caso da Baixada Santista e de São Bernardo do Campo, em São Paulo, foram registradas altas concentrações de substâncias químicas persistentes e dentre estas estão os clorofenóis (WANG et al., 2015; SILVA, 2009).

Destaca-se, também, a importância da realização de estudos referentes a novas possibilidades de redução das concentrações desses compostos, uma vez que os organoclorados podem ser transportados entre o solo, a água, os animais e os serem humanos, estando presente não apenas no ambiente, como também na cadeia alimentar e se acumularem com facilidade na gordura do organismo, devido à sua lipossolubilidade, fator esse que se tornou algo preocupante tanto pela intensidade quanto pela extensão, uma vez que, inicialmente, as substâncias eram encontradas apenas nas regiões onde eram aplicadas. Hoje, porém, há vestígios dela por todo o globo, sendo seu transporte entre os ecossistemas tão acentuado que dados mostram que $25 \%$ da produção mundial de organoclorados chega aos oceanos, por meio de poeiras e, principalmente, pela atmosfera (SILVA, 2009, FLORES et al. 2004).

\subsection{Clorofenol}

Os clorofenóis ou orto-clorofenol (Figura 1) podem ser obtidos a partir da cloração direta do fenol ou através da hidrólise alcalina de clorobenzenos são considerados compostos muito tóxicos e com elevada dificuldade de degradação sendo que, estas espécies quando submetidas às elevadas temperaturas, como é o caso da incineração, tendem a gerar clorofenóis mais nocivos e tóxicos, o que têm despertado o interesse em pesquisas relacionadas a biorremediação (AJEEL et al., 2015; PEREIRA, 2008).

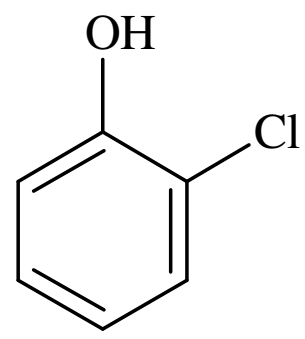

Figura 1 - Molécula de 2-clorofenol.

A utilização do 2-clorofenol é vasta, ele é o intermediário na produção de fungicidas, bactericidas, antissépticos, desinfetantes e conservantes, é empregado na produção de outros clorofenóis e resinas fenólicas, bem como na extração de enxofre e nitrogênio do carvão (WANG et al., 2015; PEREIRA, 2008) sendo que, a contaminação do ser humano pelo 2- 
clorofenol ocorre por vias respiratórias, cutâneas, por ingestão de peixes contaminados ou até mesmo por água potável que passou por processo de cloração. Assim, devido à alta toxicidade, se torna de grande necessidade a degradação do 2-clorofenol antes que este seja depositado no ambiente (AJEEL et al., 2015; PEREIRA, 2008).

\subsection{Biorremediação Enzimática}

A dificuldade de se estabelecer um padrão para o tratamento de organoclorados está relacionada à grande variedade de moléculas que são encontradas e a especificidade de cada uma delas em relação às condições e tratamentos (FREIRE et al., 2000). Os tratamentos convencionais químicos e físicos, quando aplicados a este tipo de molécula, muitas vezes não se apresentam eficientes pois, apenas trocam o poluente de fase ou transformam-nos em substâncias ainda mais nocivas. Assim, a biorremediação, por sua vez, pode resultar em completa mineralização da molécula alvo (SILVA, 2009).

A biorremediação é uma proposta de descontaminação muito promissora uma vez que, pelo emprego de sistemas biológicos, tais como fungos, bactérias, algas, leveduras e até protozoários, os compostos indesejáveis são transformados em produtos menos nocivos, de fácil remoção ou que podem permanecer no ambiente, ou até mesmo serem convertidos em produtos de valor agregado (BON et al., 2008; SUCKLING et al., 1998).

Segundo demostrado por diversos estudos, apesar das limitações para a aplicação do processo industrialmente, a biorremediação tem um futuro promissor podendo ser destacada, dentre as vantagens que o tratamento possui em relação aos tratamentos convencionais a não produção de carga orgânica. Em contrapartida, sua aplicação exige condições estritamente controladas de $\mathrm{pH}$, temperatura, nutrientes essenciais, uma vez que essas relacionam-se a viabilidade celular (BON et al., 2008).

Os processos enzimáticos, por sua vez, têm tomando grandes proporções na indústria nos últimos anos sendo empregados na indústria de papel celulose, na tecnologia têxtil e de remoção de tintas, como biocatalisadores, também são encontradas na indústria de alimentos, detergentes, couros, medicamentos, cosméticos e desenvolvimento de metodologias de análise (BON et al., 2008).

Assim, a idéia de descontaminação ambiental por tratamento enzimático, que teve início na década de 30 e que, apenas nos anos de 1970 iniciou-se a sua aplicação em moléculas específicas, tornando o tratamento mais eficiente vêm se destacando. As enzimas têm origem microbiana ou vegetal, são direcionadas a problemas específicos e podem sem utilizadas também como pré-tratamento para processos biológicos convencionais (BON et al., 2008).

As características observadas nas moléculas expostas ao tratamento enzimático são: a toxicidade, a solubilidade e a acumulação no ambiente; assim é usual serem tratadas espécies recalcitrantes e de amplas faixas de concentração ou de salinidade. Como resultado do tratamento, tem-se a redução da toxicidade e até mesmo conversão das moléculas em produtos de valor agregado (BON et al., 2008). 
Através da biorremediação, os poluentes orgânicos passam por diversas reações, simples e complexas sendo uma delas a oxidação, que tende a resultar em compostos orgânicos não nocivos, como é o caso da transformação de moléculas em gás carbônico e água (BON et al., 2008; QUINTERO et al., 2006; TANG et al., 2006). Dessa forma, os processos enzimáticos correspondem a uma das mais recentes tecnologias para o tratamento bioquímico/biológico de efluentes, sendo que as enzimas mais utilizadas para o tratamento de efluentes são as enzimas ligninolíticas, também chamadas de ligninases, pois possuem a capacidade de degradar uma vasta quantidade de substâncias tóxicas, como mostra a Tabela 1 (SÁEZ-JIMÉNEZ et al., 2015; BON et al., 2008; FREIRE et al., 2000).

Tabela 1 - Fontes poluidoras e enzimas utilizadas na biorremediação enzimática (BON et al., 2008).

\begin{tabular}{ccc}
\hline Poluente Ambiental & Fontes Poluidoras & Enzima Aplicável \\
\hline $\begin{array}{c}\text { Anilinas, fenóis, corantes, } \\
\text { pcbs, HPAS }\end{array}$ & $\begin{array}{c}\text { Indústrias químicas em geral: } \\
\text { petróleo, plástico, têxtil, corantes. }\end{array}$ & $\begin{array}{c}\text { Peroxidase, Tirosinase, } \\
\text { Lacase }\end{array}$ \\
\hline Resíduo de papel e celulose & Indústria de papel e celulose. & $\begin{array}{c}\text { Peroxidase, Lacase, } \\
\text { Celulase }\end{array}$ \\
\hline Pesticidas & Atividade agrícola em geral. & $\begin{array}{c}\text { Fosfotriesterase, } \\
\text { Peroxidase }\end{array}$ \\
\hline Resíduos sólidos e lodo & $\begin{array}{c}\text { Indústrias que originam materiais } \\
\text { celulósicos e lignocelulósicos. }\end{array}$ & $\begin{array}{c}\text { Ligninase, Lipase, } \\
\text { Lisozima, Celulase }\end{array}$ \\
\hline
\end{tabular}

As ligninases são classificadas em dois grupos: fenol-oxidases (lacase) e hemeperoxidases (lignina peroxidase - LiP, manganês peroxidase - $\mathrm{MnP}$ ). Em geral, lacases usam a molécula de oxigênio como aceptor de elétrons enquanto as peroxidades usam o peróxido de hidrogênio como co-substrato (BON et al, 2008; FERSHT, 2000; FREIRE et al., 2000).

As fenol-oxidases, lacases e as tirosinases, são oxido-redutases produzidas por plantas ou fungos utilizadas para catalisar a redução de fenóis. As lacases tem facilidade de reagir com diversos substratos e por isso são bastante utilizadas na indústria, na modificação de ligninas, na conversão de poluentes fenólicos em polímeros insolúveis em água e na obtenção de produtos de valor agregado (BON et al., 2008). A lacase é uma enzima que contém cobre em seu sítio ativo. Ela é uma oxidase que catalisa a redução do $\mathrm{O} 2 \mathrm{a}_{2} \mathrm{O}$. A lacase não apresenta especificidade quanto ao substrato, catalisando tanto estruturas fenólicas como compostos não fenólicos na presença de mediadores específicos (ZENG et al., 2016; ALVES, 2011; BAPTISTA, 2011; ROSADO; SOUZA, 2009).

As peroxidases são hemoproteínas produzidas por microrganismos ou plantas, sendo mais comum a sua produção pelo fungo da podridão branco (Basidiomicetos).Para que seu processo de catálise ocorra, requer presença de peróxido de hidrogênio. Dentre as peroxidases de origem fúngica estão a lignina peroxidase e a manganês peroxidase (BON et al., 2008; TANG et al., 2006). A produção de manganês peroxidase aparentemente está limitada a certos fungos Basidiomicetes, não havendo evidência de produção a partir de qualquer bactéria ou levedura. Esta enzima é uma glicoproteína que atua oxidando diretamente Mn (II) a Mn (III). Este promove a oxidação catalítica, formando quelatos com ácidos orgânicos como o oxalato. A manganês peroxidase, oxida somente estruturas fenólicas (ROSADO; SOUZA, 2009). 
A lignina peroxidase é uma glicoproteína que possui como grupo prostético o ferro, necessitando de peróxido de hidrogênio para sua atividade. A mesma é uma proteína com um elevado potencial de oxidação e, dessa forma, pode oxidar substratos fenólicos e não fenólicos (BAPTISTA, 2011). Apresenta potencial de oxidação suficientemente elevado para abstrair elétrons de estruturas aromáticas não fenólicas. Elas catalisam reações envolvendo transferência de hidrogênio de moléculas orgânicas para peróxidos formando água. A sua ação enzimática provem da redução cíclica do átomo de ferro no grupo hematina, na presença de $\mathrm{H}_{2} \mathrm{O}_{2}$, formando um complexo que pode oxidar uma variedade de doadores de elétrons formando água no final. Por causa da baixa especificidade do complexo enzimático peroxidase- $\mathrm{H}_{2} \mathrm{O}_{2}$, este pode promover a oxidação de uma grande variedade de poluentes orgânicos. Esta enzima tem a capacidade de degradar diversos compostos fenólicos e não fenólicos, bem como os álcoois benzílicos e de metila, provocando também rearranjos intramoleculares (ROSADO; SOUZA, 2009; RYU et al., 2008; TANG et al., 2006).

A atividade enzimática da lignina peroxidade é influenciada por diversos fatores, como concentração de peróxido de hidrogênio, pH e temperatura. Segundo Ryu et al. (2008), a oxidação do 2,4 diclorofenol com lignina peroxidase e peróxido de hidrogênio revelou que a atividade da enzima sofre grande influência da concentração de peróxido, sendo possível notar que o aumento da concentração de peróxido de hidrogênio aumenta a atividade enzimática da lignina peroxidase. Um estudo realizado por Tien e Kirk (1984), para determinação das condições ótimas da LiP, mostram a utilização da enzima para oxidação do álcool veratrílico a veratraldeído, na presença de peróxido de hidrogênio (TANG et al., 2006).

Este projeto veio dar continuidade ao trabalho de GOMES et al. (2014) que estabeleceu as melhores condições de $\mathrm{pH}$ e temperatura $\left(30^{\circ} \mathrm{C}\right.$ e $\left.\mathrm{pH} 4,2\right)$ para se realizar a oxidação do 2clorofenol presente em efluente líquido, através de método enzimático utilizando a enzima lignina-peroxidase e peróxido de hidrogênio. Com isso, o objetivo deste trabalho foi avaliar a oxidação enzimática do 2-clorofenol por ação de lignina peroxidase em processo descontínuo, avaliando-se outras condições da reação, tais como: a concentração da enzima e do peróxido de hidrogênio.

\section{MATERIAIS E MÉTODOS}

\subsection{Materiais}

Para a realização dos ensaios de biorremediação enzimática foram utilizados reagentes grau analítico e HPLC: lignina-peroxidase, 2-clorofenol (>=98 \%), metanol (grau HPLC, >= 99,9 \%) adquiridos da Sigma Aldrich (St. Louis, MO, USA) e peróxido de hidrogênio (35\% - 130vol), ácido acético (>= 99,8 \%), acetato de sódio anidro adquiridos da Dinâmica Reagentes (Campinas, SP, BR).

\subsection{Ensaios de Oxidação do Efluente Contendo 2-Clorofenol}


Nos ensaios de oxidação do 2-clorofenol foram estudadas diferentes concentrações de lignina-peroxidase (LiP) e peróxido de hidrogênio. De acordo com a literatura a melhor condição para realização de processo enzimático por lignina peroxidase deve ocorrer na faixa de temperatura de 30 a $35{ }^{\circ} \mathrm{C}$ (RYU et al., 2008; TIEN; KIRK,1984). Foram realizados quatro ensaios, descritos na Tabela 2, variando-se as concentrações de $\mathrm{LiP}$ e $\mathrm{H}_{2} \mathrm{O}_{2}$, num efluente contendo aproximadamente $20 \mathrm{mg} / \mathrm{L}$ de 2-clorofenol, baseando-se em estudo prévio realizado por Gomes et al. (2014). As reações foram conduzidas em agitador orbital com temperatura e rotação controladas, de $30^{\circ} \mathrm{C}$ e $125 \mathrm{rpm}$, respectivamente, num volume total de $20 \mathrm{~mL}$.

A fim de controlar o pH da reação utilizou-se solução tampão acetato de sódio de concentração $50 \mathrm{mmol} / \mathrm{L}$ e pH 4,2. As alíquotas para quantificação do 2-clorofenol foram retiradas em diferentes tempos: $2,4,8,12$ e 24 horas, para análise por cromatografia líquida. Também foram retiradas alíquotas, ao final das 24 horas de reação, para análise em Espectrômetro de Massas acoplado a Cromatografia Gasosa (CG/MS).

Tabela 2 - Condições empregadas na oxidação do 2-clorofenol.

\begin{tabular}{cccc}
\hline Ensaio & $\mathbf{C}_{2-\text { clorofenol }}(\mathbf{m g} / \mathbf{L})$ & $\mathbf{C}_{\mathbf{L i P}}(\mathbf{m g} / \mathbf{m L})$ & $\mathbf{C}_{\mathbf{H} 202}(\mathbf{m m o L} / \mathbf{L})$ \\
\hline 1 & 19,68 & 0,012 & 10 \\
2 & 19,30 & 0,026 & 10 \\
3 & 19,68 & 0,012 & 50 \\
4 & 19,30 & 0,026 & 50 \\
\hline
\end{tabular}

\subsection{Determinações Analíticas}

Determinação da concentração de 2-clorofenol por cromatografia líquida: as amostras de efluente contendo 2-clorofenol foram analisadas em um cromatógrafo líquido de alta eficiência (HPLC) Shimadzu composto por bombas LC-20AD, Detector UV SPD-20A, forno para coluna CTO-20A e controlador CBM-20A. A análise teve como fase móvel uma mistura composta de 50\% metanol e 50\% água, com 1\% de ácido acético para melhor resolução dos picos, e como fase estacionária uma coluna Shim-pack CLC-ODS (M) (C18) com pré-coluna Shim-pack CLC-ODS (M). O fluxo estabelecido foi de $1 \mathrm{~mL} / \mathrm{min}$ à temperatura ambiente e a detecção foi feita utilizando-se um detector UV com comprimento de onda de $284 \mathrm{~nm}$. Para que se realizasse a quantificação do 2-clorofenol presente nas amostras, construiu-se uma curva de calibração com soluções de 2-clorofenol de concentrações distintas, obtidas por diluição consecutiva da solução estoque de concentração 200 mg/L.

Caracterização via cromatografia gasosa e espectrometro de massas - CG/MS: realizou-se a análise de quatro ensaios após as 24 horas do tratamento enzimático a fim de identificar as substâncias remanescentes no efluente. O sistema utilizado na análise foi um cromatógrafo gasoso acoplado a um espectrômetro de massas da marca Shimadzu modelo GSMS-QP2010 Ultra. A coluna utiliza foi a RESTEK modelo Rtx ${ }^{\circledR}-5$ MS (30 metros, 0,25 $\mathrm{mm}$ ID e $0,25 \mu \mathrm{m})$. As condições estipuladas para as análises foram aquecimento durante 2 minutos de $25^{\circ} \mathrm{C}$ com elevação da temperatura até $200{ }^{\circ} \mathrm{C}$, temperatura na qual o equipamento permaneceu por mais 1 minuto. A temperatura de injeção foi $250{ }^{\circ} \mathrm{C}$ no modo Split utilizando uma razão de 1:3. 


\section{RESULTADOS E DISCUSSÃO}

Inicialmente, construiu-se uma curva de calibração no HPLC a fim de determinar as concentrações e, consequentemente, a redução de 2-clorofenol pelo tratamento enzimático. A curva de calibração e a equação obtidas podem ser observadas na Figura 2.

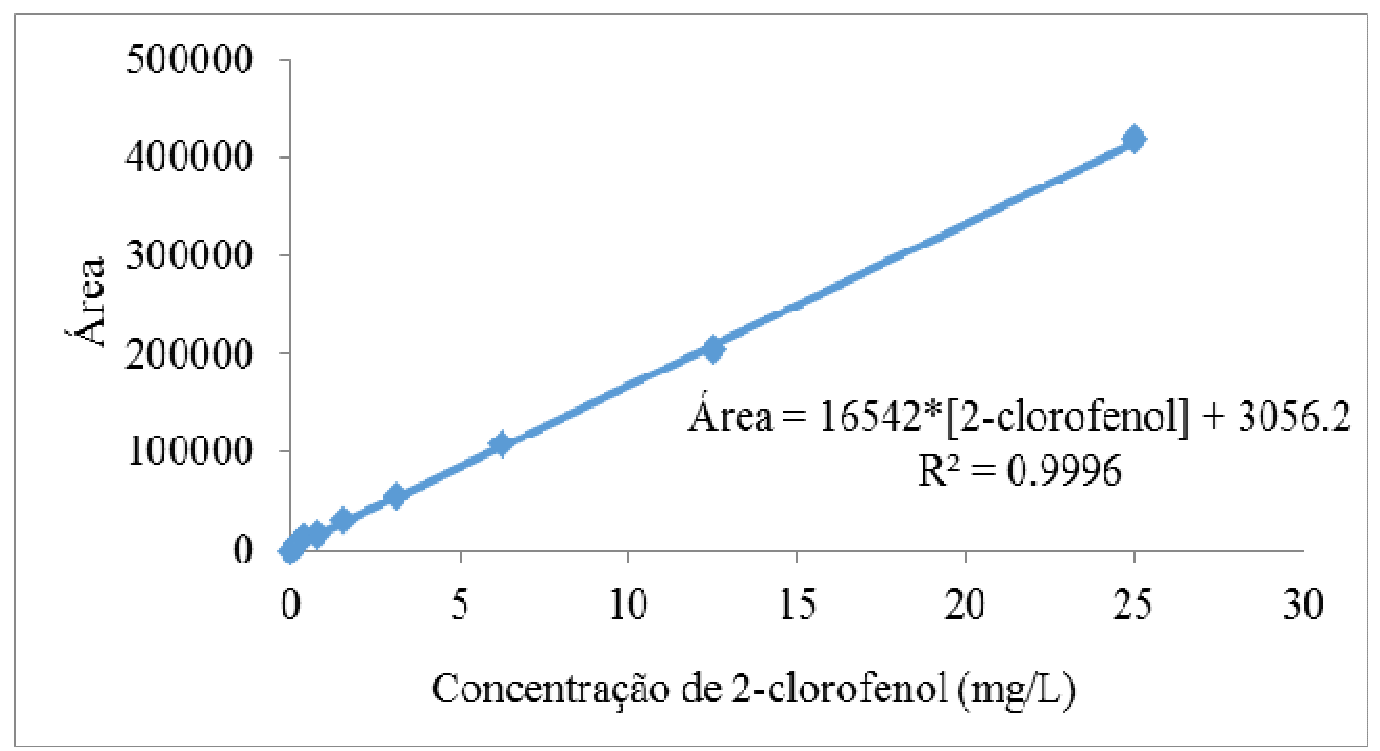

Figura 2 - Curva de calibração para o 2-clorofenol.

Pela análise feita via HPLC foram identificados picos característicos das substâncias encontradas nas amostras. A LiP e o 2-clorofenol foram analisados separadamente a fim de identificar seus picos característicos. Constatou-se que o pico da LiP aparece próximo a 2,341 minutos e o de 2-clorofenol aparece próximo a 6,459 minutos. A Figura 3 representa o cromatograma representativo para os ensaios estudados neste projeto. Utilizando as áreas dos picos obtidos via HPLC para cada um dos quatro ensaios, determinou-se as concentrações de 2-clorofenol remanescentes nas amostras após o tratamento enzimático. A Tabela 3 fornece as concentrações encontradas para os ensaios, ao longo do tempo de reação.

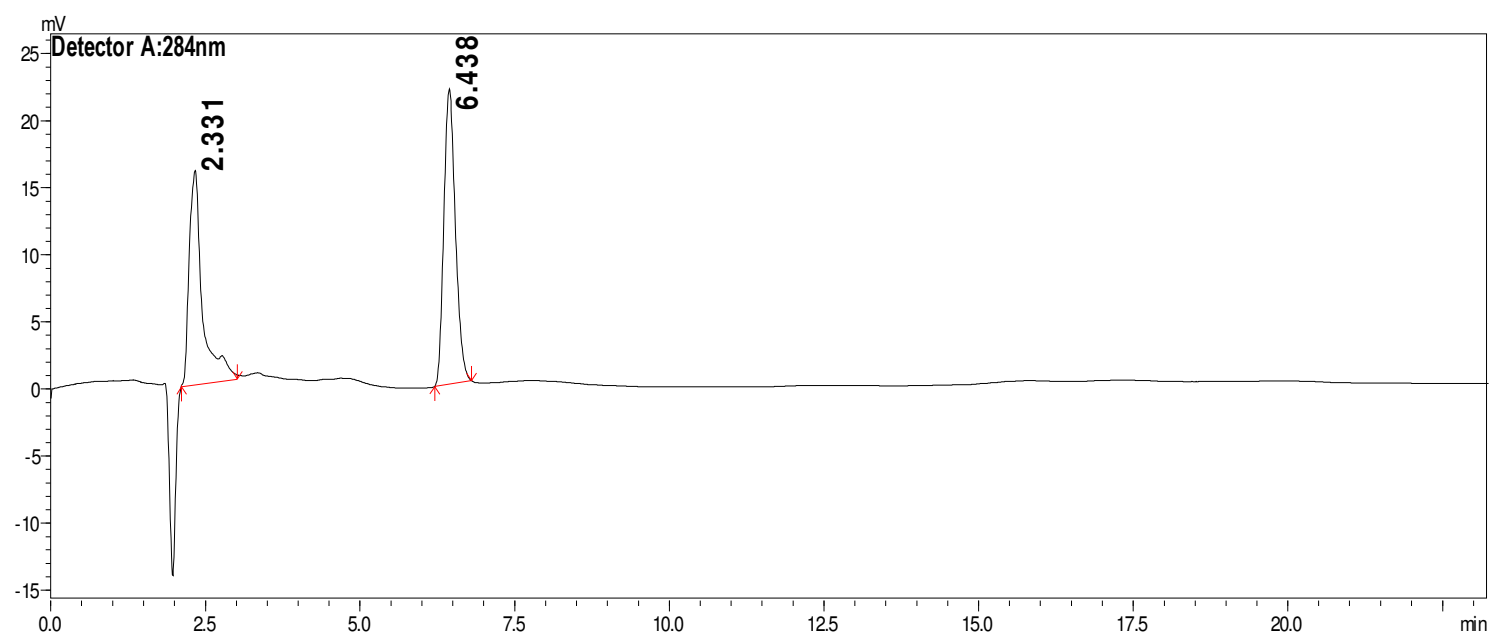

Figura 3 - Exemplo de cromatograma dos ensaios. 
Tabela 3 - Concentrações de 2-clorofenol no efluente ao longo do tempo de reação.

\begin{tabular}{ccccc}
\hline \multirow{2}{*}{ Tempo de reação $(\mathbf{h})$} & \multicolumn{4}{c}{ Concentração 2-clorofenol (mg/L) } \\
\cline { 2 - 5 } & Ensaio 1 & Ensaio 2 & Ensaio 3 & Ensaio 4 \\
\hline $\mathbf{0}$ & 19,68 & 19,30 & 19,68 & 19,30 \\
$\mathbf{2}$ & 18,65 & 18,10 & 18,32 & 6,66 \\
$\mathbf{4}$ & 18,19 & 17,11 & 17,88 & 2,91 \\
$\mathbf{8}$ & 18,09 & 16,86 & 18,00 & 1,44 \\
$\mathbf{1 2}$ & 16,96 & 15,53 & 17,90 & 1,50 \\
$\mathbf{2 4}$ & 16,55 & 5,69 & 16,89 & 0,67 \\
\hline
\end{tabular}

Legenda: (Ensaio 1 - 0,012 mg/mL LiP e $10 \mathrm{mmol} / \mathrm{L} \mathrm{H}_{2} \mathrm{O}_{2}$; Ensaio 2 - 0,026 mg/mL LiP e $10 \mathrm{mmol} / \mathrm{L} \mathrm{H}_{2} \mathrm{O}_{2}$; Ensaio 3 $0,012 \mathrm{mg} / \mathrm{mL} \mathrm{LiP}$ e $50 \mathrm{mmol} / \mathrm{L} \mathrm{H}_{2} \mathrm{O}_{2} ;$ Ensaio $4-0,026 \mathrm{mg} / \mathrm{mL} \mathrm{LiP} \mathrm{e} 50 \mathrm{mmol} / \mathrm{L} \mathrm{H}_{2} \mathrm{O}_{2}$ ).

A Figura 4 compara graficamente as porcentagens de redução de 2-clorofenol em função do tempo de reação para os quatro ensaios realizados. Pode-se observar que a condição que mais favoreceu o tratamento enzimático foi a do ensaio 4 onde, foram utilizadas as maiores concentrações de Lignina Peroxidase - LiP $(0,026 \mathrm{mg} / \mathrm{mL})$ e de Peróxido de Hidrogênio $(50 \mathrm{mmol} / \mathrm{L})$, sendo possível chegar nesta condição a uma remoção de 2-clorofenol de $96,5 \%$ para o tempo de 24 horas. Esta condição também foi eficiente em menores tempos de reação sendo alcançado $65,5 \%$ de remoção do 2-clorofenol em apenas 2 horas de tratamento.

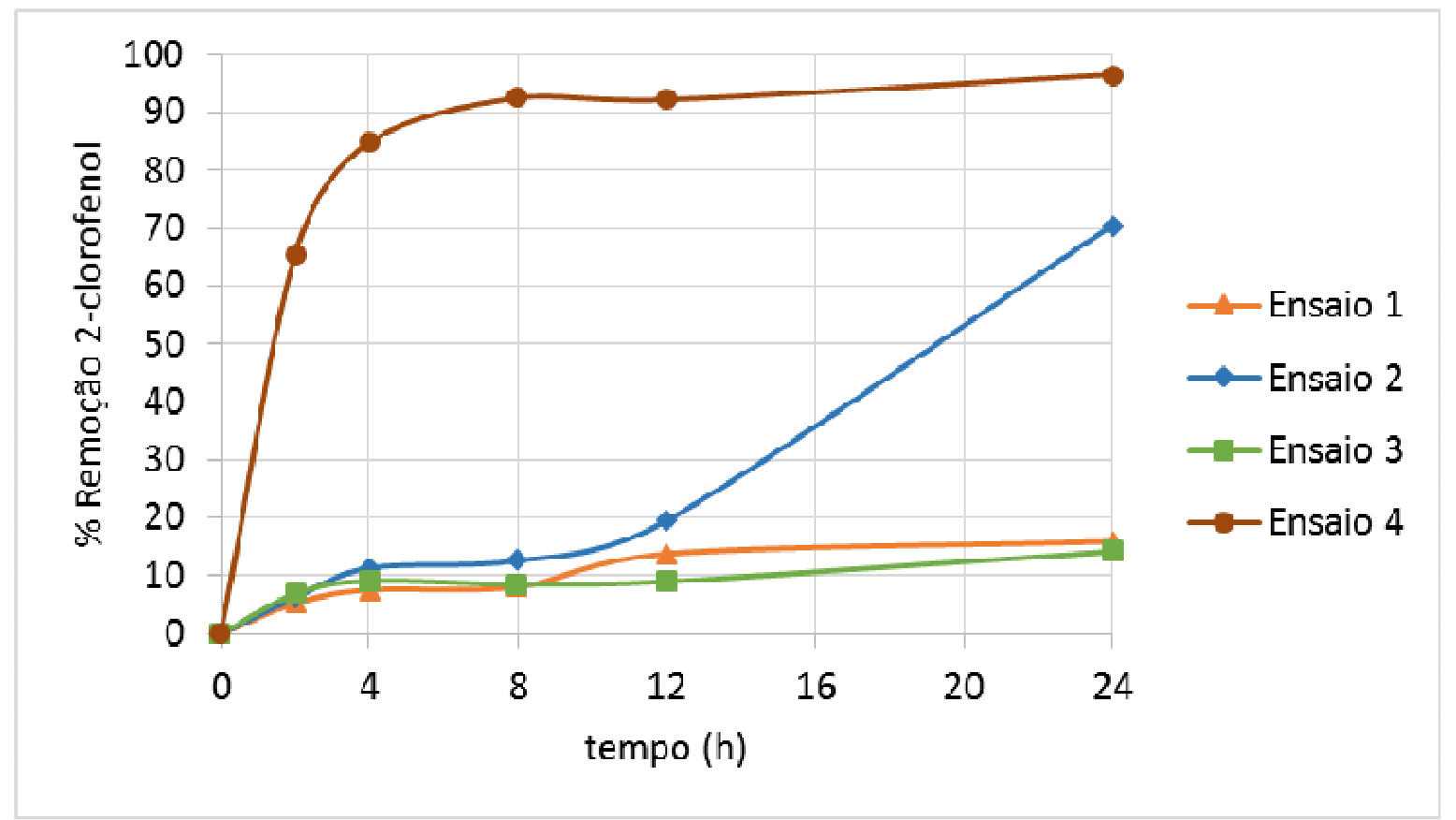

Figura 4 - Porcentagem de remoção do 2-clorofenol em função do tempo de reação.

A Figura 5 apresenta a comparação das porcentagens de remoção do 2-clorofenol para os quatro ensaios após 24 horas de reação enzimática. 


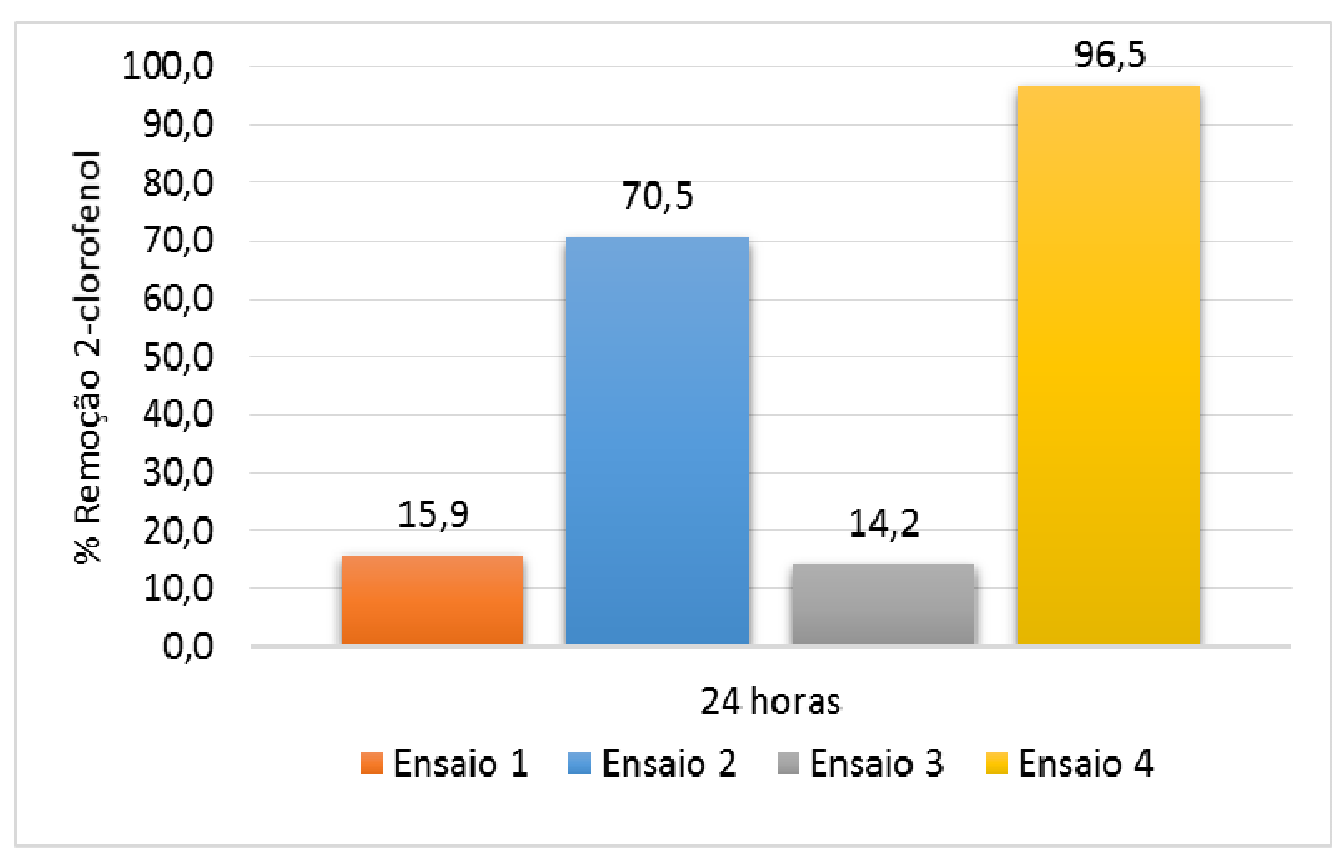

Figura 5 - Porcentagem de remoção do 2-clorofenol após 24 horas de reação enzimática. (Ensaio 1 - 0,012 mg/mL LiP e $10 \mathrm{mmol} / \mathrm{L} \mathrm{H}_{2} \mathrm{O}_{2}$; Ensaio $2-0,026 \mathrm{mg} / \mathrm{mL} \mathrm{LiP} \mathrm{e} 10 \mathrm{mmol} / \mathrm{L}$ $\mathrm{H}_{2} \mathrm{O}_{2}$; Ensaio 3 - 0,012 mg/mL LiP e $50 \mathrm{mmol} / \mathrm{L} \mathrm{H}_{2} \mathrm{O}_{2}$; Ensaio $4-0,026 \mathrm{mg} / \mathrm{mL}$ LiP e 50 $\mathrm{mmol} / \mathrm{L} \mathrm{H}_{2} \mathrm{O}_{2}$ )

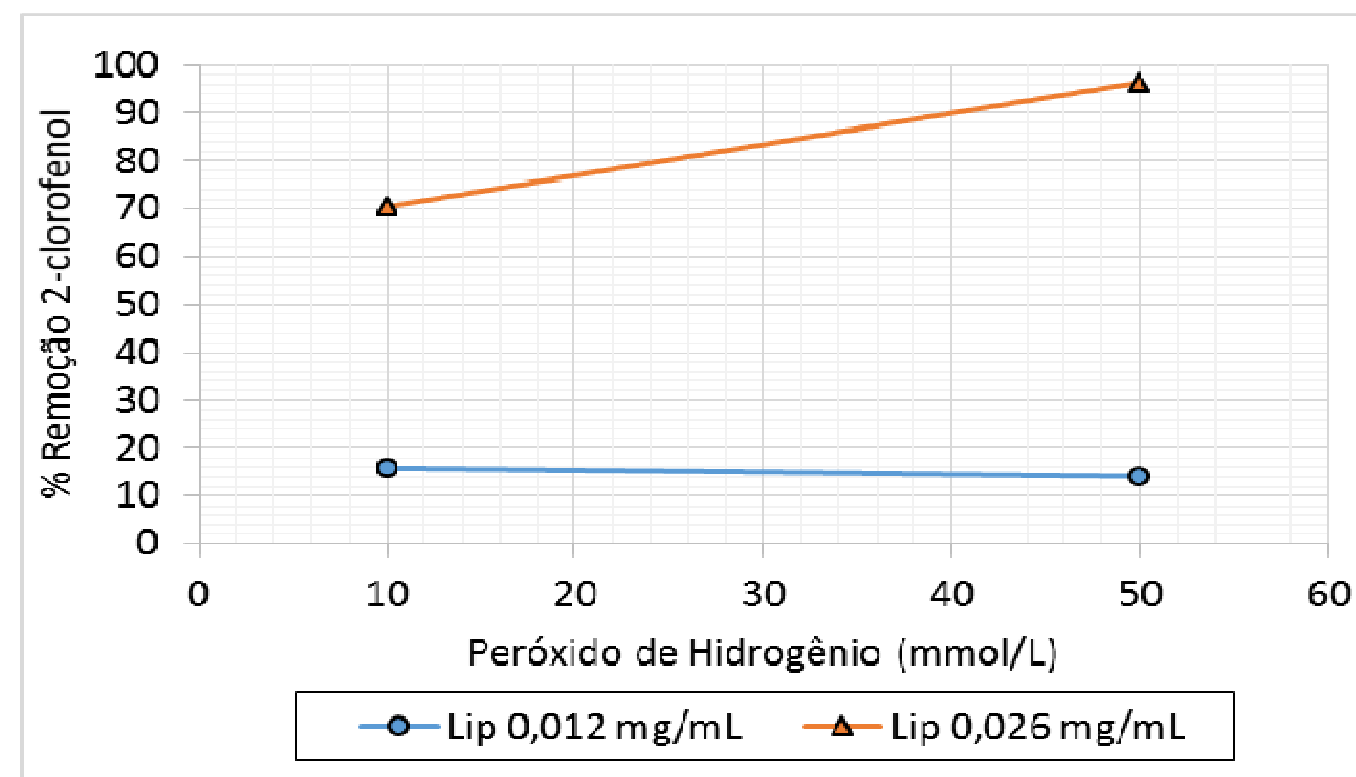

Figura 6 - Porcentagem de remoção do 2-clorofenol após 24 horas de reação enzimática.

Pode-se concluir, pela Figura 6, que a concentração de lignina-peroxidase (LiP) é um fator limitante para a oxidação enzimática do 2-clorofenol, pois quanto maior a concentração da enzima maior foi o percentual de remoção da molécula alvo do efluente. O peróxido de hidrogênio também é uma variável importante no processo pois com a maior concentração de peróxido houve uma aumento de $26 \%$ da remoção do 2-clorofenol. Pela comparação dos ensaios com maior e menor concentração de peróxido, vista na Figura 6, pode-se observar que para baixas concentrações de enzima o peróxido de hidrogênio passa a atuar como um 
inibidor da reação, reduzindo a porcentagem de remoção atingida, porém com a maior concentração de enzima a maior concentração de peróxido favoreceu a oxidação do 2clorofenol (GOMES et al., 2014, RYU et al., 2008).

Pela análise dos cromatogramas e dos espectros obtidos via GCMS foi possível identificar e quantificar as espécies presentes na amostra analisada, sendo observados, para isso, os picos e seus respectivos tempos de retenção. Os dados apresentados na Figura 7 são os cromatogramas $\mathrm{CG} / \mathrm{MS}$ referentes aos ensaios 1, 2, 3 e 4 após estes terem sido submetidos a 24 horas de tratamento enzimático por lignina-peroxidase a $30^{\circ} \mathrm{C}$ e $\mathrm{pH} 4,2$.
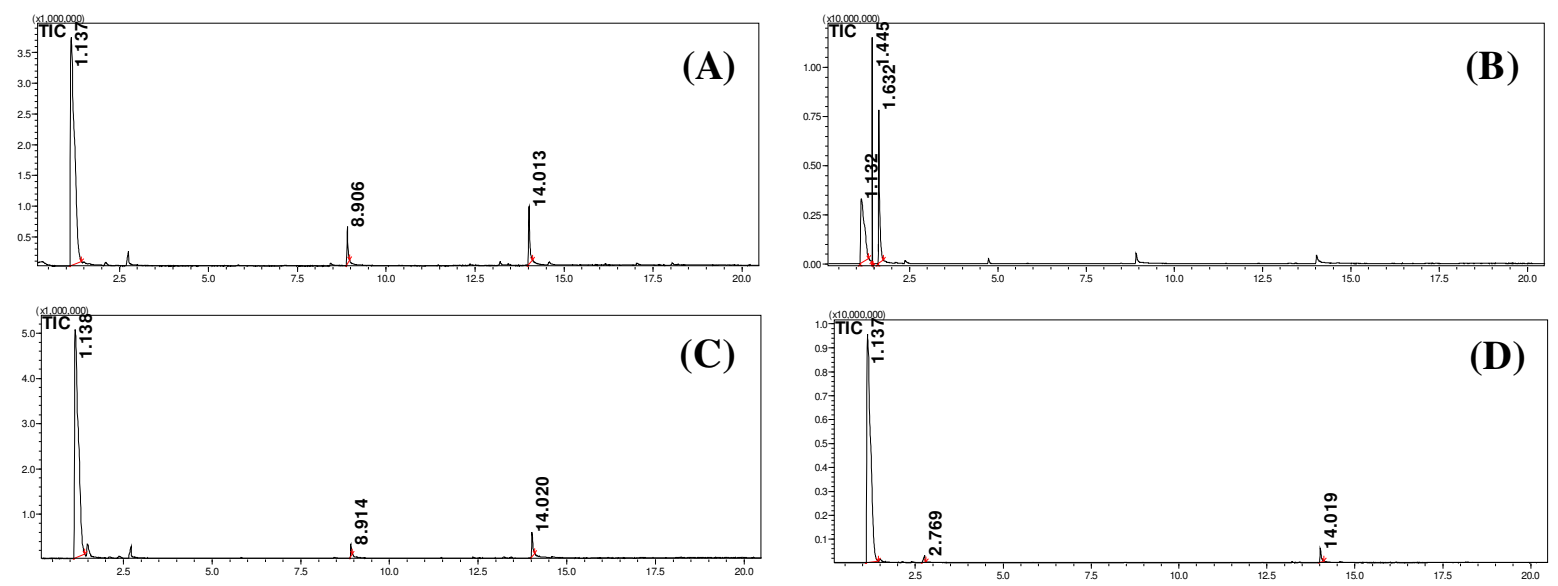

Figura 7 - Cromatogramas CG/MS: A) Ensaio 1 - 0,012 mg/mL LiP e $10 \mathrm{mmol} / \mathrm{L} \mathrm{H}_{2} \mathrm{O}_{2}$; B)

Ensaio $2-0,026 \mathrm{mg} / \mathrm{mL} \mathrm{LiP} \mathrm{e} 10 \mathrm{mmol} / \mathrm{L} \mathrm{H}_{2} \mathrm{O}_{2}$; C) Ensaio $3-0,012 \mathrm{mg} / \mathrm{mL}$ LiP e 50 $\mathrm{mmol} / \mathrm{L} \mathrm{H}_{2} \mathrm{O}_{2}$ e D) Ensaio 4 - 0,026 mg/mL LiP e $50 \mathrm{mmol} / \mathrm{L} \mathrm{H}_{2} \mathrm{O}_{2}$.

Os espectros de massas referentes a cada pico obtido para as amostras via análise GC/MS foram comparados com os espectros fornecidos pelo banco de dados do equipamento. A Figura 8 traz os espectros de massa obtidos via análise CG/MS e as possíveis substâncias encontradas nas amostras do ensaios 1, 2, 3 e 4 após 24 horas de reação enzimática. Supõe-se que, após a reação, podem ser encontrados ácido acético, benzaldeído, 2-clorofenol e ácido ftálico, sendo estes encontrados em proporções diferentes dependendo da efetividade do tratamento. Outras moléculas como gás carbônico, água e cloro podem ter sido formadas, porém não foram quantificadas neste estudo.

Como pode ser observado na Figura 7(D) o pico correspondente ao 2-clorofenol não aparece no cromotagrama, confirmando a remoção quase completa do 2-clorofenol, como discutido anteriormente nos percentuais de remoção. Esta condição então foi a mais adequada encontrada neste estudo para a biorremediação enzimática do efluente estudado. 

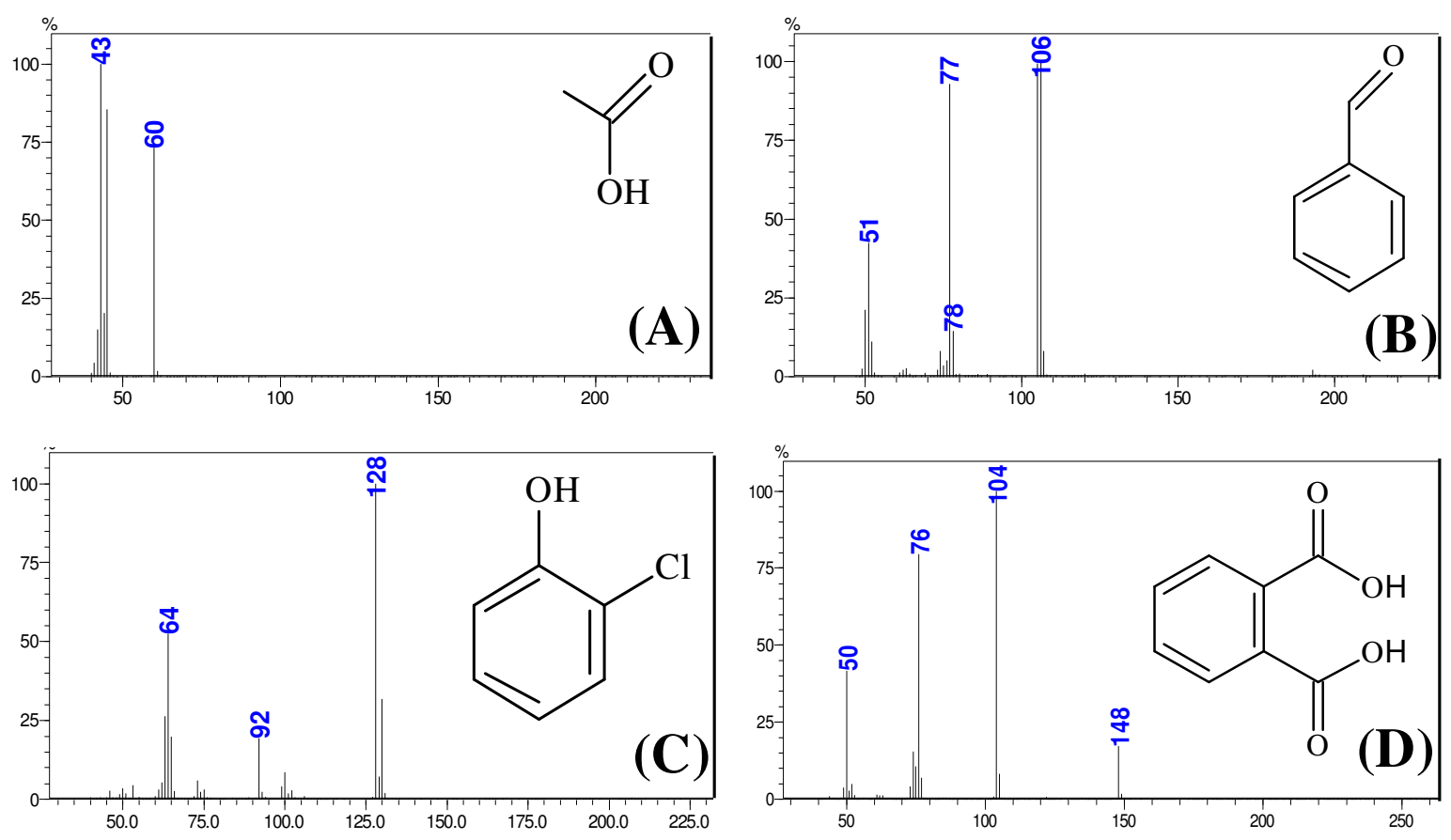

Figura 8 - Espectros de massa das substâncias encontradas no efluente após 24 horas de reação: A) Pico em 2,9 min (Ácido Acético); B) Pico em 8,5 min (Benzaldeído); C) Pico em 8,9 min (2-clorofenol) e D) Pico em 14 min (Ácido Ftálico).

\section{CONCLUSÕES}

A caracterização e quantificação das amostras coletadas durante a oxidação enzimática permitiram o acompanhamento da remoção do 2-clorofenol ao longo do tempo de reação, mostrando que a máxima remoção é obtida após 24 horas de enzimático.

Portanto, para mensurar a efetividade do tratamento analisou-se o percentual de remoção de 2-clorofenol após 24 horas de reação enzimática. Observou-se que a condição que apresentou melhores resultados foi aquela em que se empregaram as maiores concentrações de lignina-peroxidase e peróxido de hidrogênio. Nos ensaios com maior concentração de enzima, $0,026 \mathrm{mg} / \mathrm{mL}$, o efeito do aumento da concentração de peróxido de hidrogênio foi positivo, sendo que, com o uso de 10 e $50 \mathrm{mmol} / \mathrm{L}$ de $\mathrm{H}_{2} \mathrm{O}_{2}$ foram registrados percentuais de redução de $70,5 \%$ e $96,5 \%$, respectivamente. Vale salientar que o peróxido de hidrogênio é indispensável no mecanismo da oxidação enzimática do 2-clorofenol pela lignina-peroxidase.

A cromatografia gasosa acoplada ao espectrômetro de massas possibilitou a identificação de possíveis produtos da decomposição do 2-clorofenol. Foram comparados os espectros obtidos para os quatro ensaios após terem reagido durante 24 horas, com os espectros existentes no banco de dados do sistema CG/MS. Para os ensaios 1, 2 e 3 foram identificados o ácido acético, o benzaldeído, o 2-clorofenol e o ácido ftálico. Para o ensaio 4, onde grande parte do 2-clorofenol foi eliminado, identificou-se apenas os picos de ácido acético, benzaldeído e ácido ftálico. Propôs-se que o ácido acético é proveniente do tampão e tanto o benzaldeído quando o ácido ftálico são produtos da reação enzimática. Além do 2- 
clorofenol, não foi identificada qualquer outra molécula orgânica clorada, sendo verificada a eliminação dos átomos de cloro do efluente, objetivo central deste projeto.

\section{AGRADECIMENTOS}

Ao Centro Universitário FEI pelo suporte para o desenvolvimento do trabalho.

\section{REFERÊNCIAS}

AJEEL, M.A., AROUA, M.K., DAUD, W.M.A.W. Anodic Degradation of 2-Chlorophenol by Carbon Black Diamond and Activated Carbon Composite Electrodes. Electrochimica Acta, v.180, p. 22-28, 2015.

ALVES, A. L. Produção, purificação e caracterização de uma lacase de Phlebia rufa (Pers.) MP Christ. 2011. 111 f.Dissertação (Mestrado em Biologia Clínica Laboratorial). Universidade de Trás-os-Montes e Alto Douro, Vila Real, 2011.

BAPTISTA, N. M. de Q. Produção das enzimas lignina peroxidase e lacase por fungos filamentosos. 2011. 38 f. Monografia (Especialização em Micologia) - Universidade Federal de Pernambuco, Recife, 2011.

BON, E. P. S; FERREIRA, M. A.; CORVO, M. L. Enzimas em Biotecnologia: produção aplicação e mercado. Rio de Janeiro: Interciência Ltda., 2008.

FERSHT, A. Structure and mechanism in protein science: A guide to enzymes calalysis and protein folding. New York: W.H. Freeman and Company, 2000.

FLOCK, C., BASSI, A., GIJZEN, M. Removal of aqueous phenol and 2-chlorophenol with purified soybean peroxidase and raw soybean hulls. Journal of Chemical Technology and Biotechnology, v.74, p.303-309, 1999.

FLORES, A.V.; RIBEIRO, J.N.; NEVES, A.A.; QUEIROZ, E.L.R. Organoclorados: Um problema de saúde pública. Ambiente \& Sociedade, v. 7, n. 2, p. 111-124, jul./dez. 2004.

FREIRE, R., S.; PELEGRINI, R.; KUBOTA, L.T.; DURÁN, N. Novas tendências para o tratamento de resíduos industriais contendo espécies organocloradas. Química Nova, v. 23, n. 4, p. 504-510, 2000.

GAO, J., TEPLYAKOV, A.V. Thermal transformations of 2-chlorophenol on a surface of ZnO powder catalyst. Catalysis Today, v. 238, p. 111-117, 2014.

GOMES, A.N.; PASQUOTO, C.G.; MATEO, L.C.; SASSI, L.B. Uso de reator enzimático a membrana para o tratamento de efluente líquido contaminado por organoclorado. 2014. 103 f. Trabalho de Conclusão de Curso (Graduação em Engenharia Química) - Centro Universitário da FEI, São Bernardo do Campo, 2014.

PEREIRA, I. Estudo da degradação do 2-clorofenol através de processos oxidativos avançados. 2008. 83 f. Dissertação (Mestrado em Engenharia de Processos Químicos e Bioquímicos) - Escola de Engenharia Mauá, Centro Universitário do Instituto Mauá de Tecnologia, São Caetano do Sul, 2008.

QUINTERO, J.C., FEIJOO, G., LEMA, J.M. Producción de enzimas ligninolíticas com hongos basidiomicetos cultivados sobre materiales lignocelulósicos. Revista de la Facultad de Química Farmacéutica, v.13, n.2, p. 61-67, 2006.

ROSADO, F. R.; SOUZA, A. F. Utilização de fungos basidiomicetes em biodegradação de efluentes têxteis. Revista em Agronegócios e Meio Ambiente, v. 2, n. 1, p. 121-139, jan./abr. 2009. 
RYU K.; KANG, J.H.; WANG, L.; LEE, L. Expression in yeast of secreted lignin peroxidase with improved 2,4-dichlorophenol degradability by DNA shuffling. Journal of Biotechnology, V.135, p. 241-246, 2008.

SÁEZ-JIMÉNEZ, V., BARATTO, M.C., POGNI, R., RENCORET, J., GUTIÉRREZ, A., SANTO, J.I., MARTÍNEZ, A.T., RUIZ-DUEÑAS, F.J. Demonstration of Lignin-toPeroxidase Direct Electron Transfer: A transient-state kinetics, directed mutagenesis, EPR, and NMR study. The Journal ff Biological Chemistry, v. 290, n.38, p. 2320123213, 2015.

SILVA, R. R. da. Biorremediação de solos contaminados com organoclorados por fungos basidiomicetos em biorreatores. 2009. $186 \mathrm{f}$. Tese (Doutorado em Biodiversidade Vegetal e Meio Ambiente, Área de Concentração de Plantas Avasculares e Fungos) Instituto de Botânica da Secretaria do Meio Ambiente, São Paulo, 2009.

SUCKLING, C. J; GILBSON, C. L.; PITT, A. R. Enzime Chemistry: Impact and applications. 3.ed. London: Blackie Academic \& Professional, 1998.

TANDJAOUI, N., ABOUSEOUD, M., COUVERT, A., AMRANE, A., TASSIST, A. A new combined green method for 2-Chlorophenol removal using cross-linked Brassica rapa peroxidase in silicone oil. Chemosphere, v.148, p.55-60, 2016.

TANG, L., ZENG, G.M., SHEN, G.L., ZHANG, Y., HUANG, G.H., LI, J.B. Simultaneous amperometric determination of lignin peroxidase and manganese peroxidase activities in compost bioremediation using artificial neural networks. Analytica Chimica Acta, v.579, p.109-116, 2006.

TIEN, M.; KIRK, T.K. Lignin-degrading enzyme from Phanerochaete chrysosporium: Purification, characterization, and catalytic properties of a unique $\mathrm{H}_{2} \mathrm{O}_{2}$-requiring oxygenase. PNAS - Proceedings of the National Academy of Sciences of the United States of America, Biochemistry, v.81, p. 2280-2284, april 1984.

WANG, Y.K., PAN, X.R., SHENG, G.P., LI, W.W., SHI, B.J., YU, H.Q. Development of an energy-saving anaerobic hybrid membrane bioreactors for 2-chlorophenol-contained wastewater treatment. Chemosphere, v.140, p.79-84, 2015.

ZENG, J.; ZHU, Q.; WU, Y.; LIN, X. Oxidation of polycyclic aromatic hydrocarbons using Bacillus subtilis CotA with high laccase activity and copper independence. Chemosphere, v.148, p.1-7, 2016. 


\title{
STUDY OF LIGNIN-PEROXIDASE FOR REMOVAL OF 2- CHLOROPHENOL IN LIQUID EFFLUENT
}

\author{
J. M. DE OLIVEIRA ${ }^{1}$, A. A. MORANDIM GIANNETTI ${ }^{1}$, A. C. LUCARINI ${ }^{1, *}$ \\ ${ }^{1}$ FEI University, Department of Chemical Engineering \\ *E-mail: lucarini@fei.edu.br
}

\begin{abstract}
In this work, we studied the removal of 2-chlorophenol in liquid effluent with lignin-peroxidase as biocatalyst. Therefore, we proposed the enzymatic bioremediation by discontinuous process of effluent containing $20 \mathrm{mg} / \mathrm{L}$ of 2-chlorophenol, using Lignin peroxidase $(\mathrm{LiP})$ concentrations between 0.012 and $0.026 \mathrm{mg} / \mathrm{mL}$ and of hydrogen peroxide $\left(\mathrm{H}_{2} \mathrm{O}_{2}\right)$ between 10 and $50 \mathrm{mmol} / \mathrm{L}$, at $30^{\circ} \mathrm{C}$ and $\mathrm{pH}$ of 4.2. The samples were collected for 2 , 4, 8, 12 and 24 h reaction times. Chromatographic analysis revealed 96,5\% reduction of 2chlorophenol when concentrations of $0.026 \mathrm{mg} / \mathrm{mL} \mathrm{LiP}$ and $50 \mathrm{mmol} / \mathrm{L} \mathrm{H}_{2} \mathrm{O}_{2}$ were used. We observed effective results only after $24 \mathrm{~h}$ of treatment, regardless of LiP and $\mathrm{H}_{2} \mathrm{O}_{2}$ concentrations. Analysis using mass spectroscopy revealed possible formations of benzaldehyde and phthalic acid, and almost all the 2-chlorophenol consumption was confirmed after 24 h of treatment in the ideal condition.
\end{abstract}

KEYWORDS: Lignin peroxidase; 2-chlorophenol; Bioremediation; Biotransformation. 